\title{
Giant fibroadenoma presenting like fungating breast cancer in a Nigerian teenager
}

\author{
*Arowolo $\mathrm{OA}^{1}$, Akinkuolie $\mathrm{AA}^{1}$, Adisa $\mathrm{AO}^{1}$, Obonna $\mathrm{GC}^{1}$, Olasode B J
}

1. Department of Surgery, Obafemi Awolowo University Ile Ife, Osun State, Obafemi Nigeria

2. Departmenmt of Morbid Anatomy, Obafemi Awolowo University, Ile Ife, Osun State, Obafemi Nigeria

\begin{abstract}
Background: Giant fibroadenoma of the breast is a rare benign breast tumour which seldom grows to a giant size, it is even rarer for this benign tumour to grow rapidly, ulcerate spontaneously and present like a fungating breast tumour in a way mimicking breast cancer.

Case presentation: This is a presentation of a 14 year old premenarchal girl with a massive ulcerating and fungating left breast mass that was initially thought to be a fungating locally advanced breast carcinoma on clinical examination. Further examination of the morphology of the resected surgical specimen and histological examination confirmed it to be giant fibroadenoma of the breast. It was successfully managed by partial mastectomy and breast reconstruction with an excellent result and a high degree of patient satisfaction was achieved.

Conclusion: Though a rare clinical entity benign breast tumour can present like a fungating breast cancer and this must be bore in mind especially in young adolescent patients presenting with ulcerating breast tumour.

Key word: Giant fibroadenoma, fungating tumour, Nigeria teenager.

African Health Sciences 2013; 13(1): 162 - 165 http://dx.doi.org/10.4314/ahs.v13i1.23
\end{abstract}

\section{Introduction}

Fibroadenoma is the most common breast mass in the adolescent ${ }^{1,2,3}$. Giant or juvenile fibroadenoma accounts for 0.5-2 per cent of all cases of fibroadenomas ${ }^{4}$. This subtype is characterized by its large size and rapid growth.,6 Giant breast tumours are rapidly growing breast masses with diameters exceeding $5 \mathrm{~cm}$ and/or weights of more than 500 gm. ${ }^{7,8}$ They can rarely grow to immense proportions, resulting in congestion and ulceration of skin by centrifugal pressure. ${ }^{7}$ Such an enlargement of the breast can be due to giant fibroadenoma, cystosarcoma phylloides or virginal hypertrophy, occurring in that order of Frequency. ${ }^{8-10}$ These tumours are believed to be closely related variants of a similar pathologic process. ${ }^{10}$ They are characterized by proliferation of epithelial and connective tissue elements in varying proportions. The peak age-incidence is reported to be 17-20 years and less than $5 \%$ of these giant fibroadenoma occurs below 18 years.$^{11}$

\footnotetext{
*Corresponding author:

Dr. Arowolo Olukayode Adeolu

Department of Surgery

College of Health Sciences

Obafemi Awolowo University

Tel : +2348037171477

E-mail: arowolodoctor1@yahoo.com
}

It is very rare for premenarchal teenage girls to present with a giant fungating benign breast lesion which could easily be confused with breast carcinoma. This paper reported a case of fungating giant fibroadenoma of the breast and it also outlines the challenges encounter during the clinical management of the patient. Carcinoma of the breast on the other hand has been on the increase so much that it has assumed an epidemiological dimension. In developing country such as Nigeria late presentation of breast cancer has remained a rule rather than exception and it is very common for patient to present with fungating breast lesion.

\section{Case report}

A 14 year old Junior Secondary School student of Yoruba ethnicity presented in the Accident and Emergency unit of the Hospital with 1 year history of unilateral left breast swelling which has become rapidly progressive in the last 1 month with spontaneous ulceration of the overlying skin and bleeding 5 days prior to presentation. There was no preceding history of trauma to the breast. She had a month history of intermittent left breast pain which was occasionally severe enough to interfere with her daily activities and also disturbed her sleep. There was no Axillary swelling or swelling in any other part of her body. She is yet to attain menarche when the 
breast swelling was noticed. There was no previous exposure to any form of exogenous oestrogen based hormonal contraceptive

Physical examination essentially revealed an exhausted, pale, weak and tachycardic (pulse rate of 100 per minute, small volume but regular) young girl. She was not in painful distress. The left breast was hugely enlarged. Clinical measurement of the enlarged breast was about $30 \mathrm{~cm}$ by $20 \mathrm{~cm}$ (radius $10 \mathrm{~cm}$ ) (figure 1). This gives approximate breast volume of $3,000 \mathrm{mls}$ where as the average breast volume in women in a study by katariya et al. using mammography measurements of length, radius and calculating with formula $1 / 3 \mathrm{nr}^{2} \mathrm{l}(\mathrm{r}=$ radius, $1=$ length on mammogram) which correlate well with clinical measurement is $690 \mathrm{mls}-790 \mathrm{mls}^{12}$. The breast was enlarged and also reaching to the level of the pelvis of the patient. The left breast mass was firm in consistency, not tender, not attached to the underlying pectoralis major muscle. There was ulceration of the skin at the central part of the breast involving and destroying the nipple areolar complex (figure 1). There was associated purulent discharge, slough and necrotic tissue over the ulcer with occasional contact bleeding. The right breast was normal with no palpable mass. The lymph node of the axilla and the supraclavicular region were not palpably enlarged.

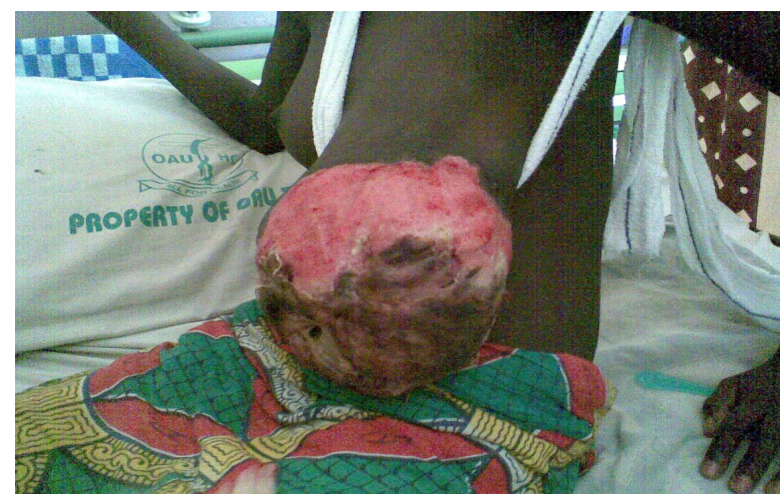

Figure 1: Picture showing huge giant fibroadenoma of the breast reaching below the umbilical level to the pelvis of the patient with destruction of nipple areolar complex

The Initial clinical diagnosis was fungating breast cancer with possible differential diagnosis of cystosarcoma phylloides, primary burkitt lymphoma and carcinoma of the breast. Her haematocrit was $25 \%$. Electrolyte and urea were essentially within normal limit. Chest x ray was normal. Computerised axial tomography scan and magnetic resonance imaging of the breast tissue which could have further characterised the nature of the fungating breast tumour could not be done because this investigative modality were lacking in our centre. An incisional biopsy showed hyperplasia of stroma and the epithelial lining the ducts with no evidence of malignancy.

She was adequately resuscitated with intravenous fluid and antibiotics (intravenous Ciprofloxacin at $10 \mathrm{mg}$ per kilogram body weight and intravenous Metronidazole at $7.5 \mathrm{mg}$ per kilogram body weight). She then had complete wide excision of the tumour with breast reconstruction. Operative findings included massively enlarged outer lobule of the left breast with ulcerative destruction of the nipple areolar complex. The deeper lobular structure of the breast was preserved. The excised breast tissue measures $25 \mathrm{~cm}$ by $30 \mathrm{~cm}$ and weighs 2,500gm (figure 2).

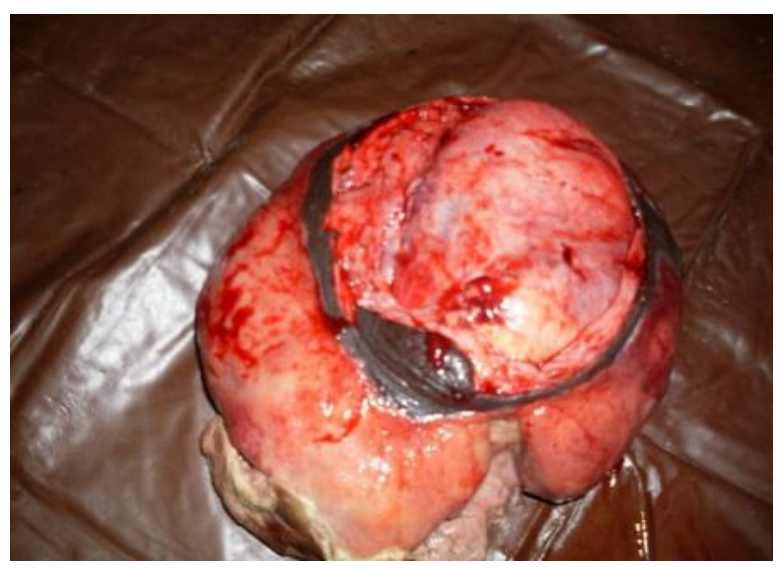

Figure 2: Excised breast mass measuring $20 \mathrm{~cm}$ x $30 \mathrm{~cm}$ and weighs $2,500 \mathrm{gm}$

She had an uneventful post operative period and pain control using analgesic (intravenous Pentazocine $0.5 \mathrm{mg}$ per $\mathrm{kg}$ body weight.). She is still being followed up in the surgical outpatient clinic (figure 3). The histopathology showed fibroadenoma benign fibroepithelial lesion and ductal hyperplasia it also showed some degree of infection with leukocytic infiltartion (figure 4). 


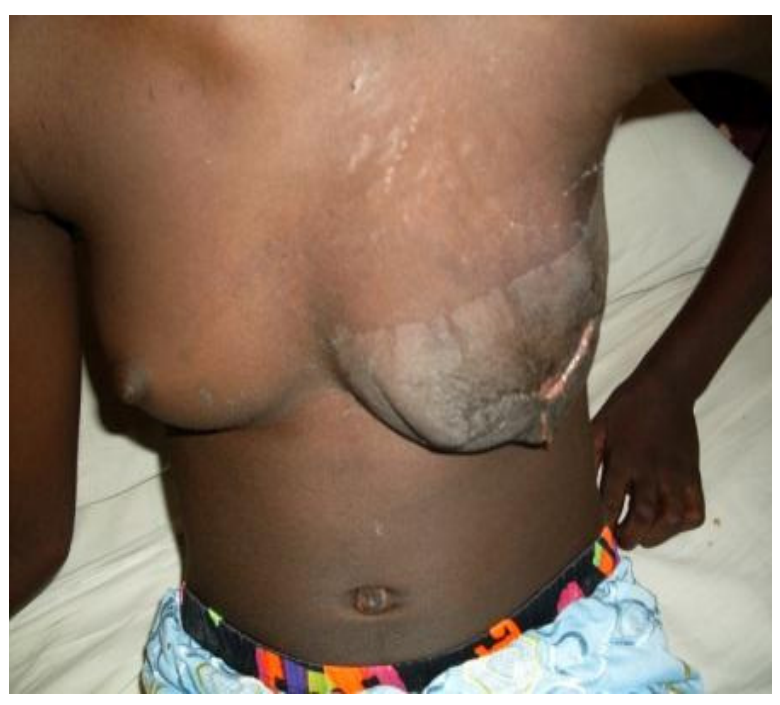

Figure 3: Post operative condition of the patient being followed up in the outpatient clinic

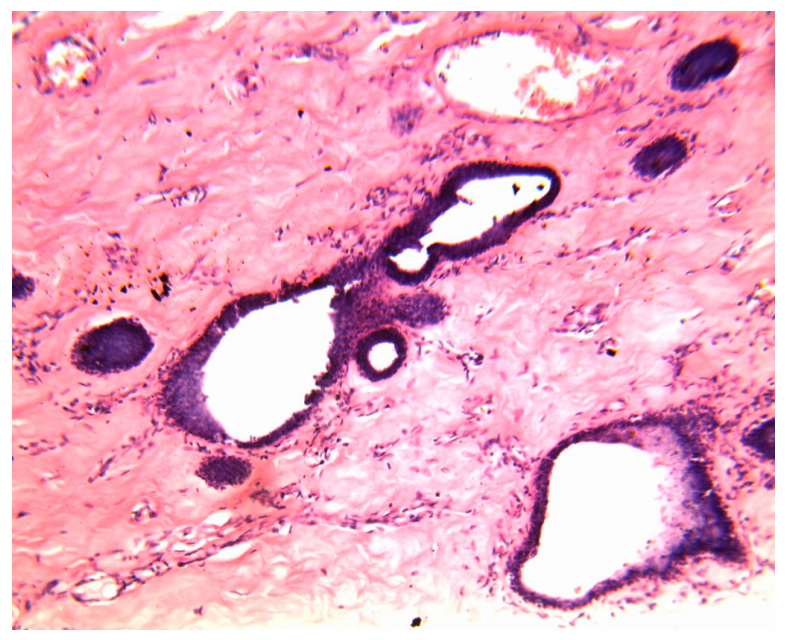

Figure 4: Shows fibroadenoma with ductal hyperplasia at magnification of $x 100$

\section{Consent}

"Written informed consent was obtained from the parent of this patient for publication of this case report and accompanying images".

\section{Discussion}

For a variety of reasons, giant breast tumours continue to pose a challenge in diagnosis and management. These tumours are poorly understood because of their rarity and unpredictable behaviour. Their rapid growth, associated with skin congestion and ulceration, and tendency to recur, gives rise to a suspicion of malignancy. ${ }^{13,14}$
This case posed a diagnostic challenge initially since the breast swelling was of short duration of 1 year and there was no previous history of breast asymmetry in this patient. More interesting is the fact that the tumour grew rather rapidly 2 months prior to presentation leading to ulceration of the skin and destruction of nipple areolar complex despite absence of history of trauma and denial of application of caustic herbal preparation by the patient. Even though the patient denied this our strong suspicion is that, as the usual practice is in developing country such as Nigeria this patient first patronised local traditional doctors who applied local caustic lotion to the breast causing extensive necrosis and ulceration. It is not uncommon for patient in developing world like Nigeria to try local and herbal treatment at home but deny when asked for fear of being reprimanded.

After the skin ulceration there was history of rapid and progressive expansion of the fleshy part of the tumour that it outgrew and projected out of the skin cover. Hence at presentation our initial clinical diagnoses were fungating malignant breast tumour most likely burkitt's lymphoma, phylloides tumour and carcinoma of the breast in that order. It was even more confusing because the initial histological diagnosis of incisional biopsy was non conclusive although it suggested a benign lesion.

Owing to the varied histological features seen in giant breast tumours, there have been widely varying interpretations and diagnoses by pathologists ${ }^{16}$. This has led to inappropriate, and at times unnecessarily radical, surgical therapy. In the 1950s, breasts were amputated for this relatively non life threatening condition. ${ }^{17}$ However; the present trend is towards more conservative management. This patient was managed by excision of the tumour which was well delineated from the underlying normal breast tissue without unduly compressing it. Breast reconstruction was done by using 0 - chromic catgut in hexagonal fashion to re - suspend the remaining breast tissue. This achieved satisfactory result by making the residual breast protuberant.

Breast mass is not a common problem in the paediatric age group. Although primary breast cancer in this group has been reported, it is extremely rare ${ }^{13,14}$. The majority of breast masses in the young arise from congenital malformations or benign neoplasm. 2,3 However, a breast lump is of great concern to the parents and physicians because of potential malignancy. ${ }^{13}$ 


\section{Conclusion}

It should be noted that huge masses growing rapidly inside the breast can cause pressure atrophy of the surrounding normal breast tissue with subsequent ulceration of the overlyin skin thus mimicking a malignant lesion of the breast and confuse undiscerning physicians. Detailed clinical examination of all breast lumps is important before deciding on appropriate surgical management. When proper pre - surgical planning is done even in face of a bening fungating breast lesion before operating upon the patient, the breast can be saved with good cosmetic outcome as seen in this particular case.

\section{Reference}

1. Gobbi D, Dallagna P, Alaggio R. Giant fibroadenoma of the breast in adolescent : report of 2 cases. J paed surg. 2009 ; 44(2) : 30 41.

2. Ferguson CM, Powell RW. Breast mass in young women. Arch Surg 1989; 124: 1338-41.

3. Palmer ML, Tsangaris TN. Breast biopsy in women 30 years old or less. Am J Surg 1993; 165: 708-1 2.

4. Baxi M, Agarwal A, Mishra A, et al. Multiple bilateral giant juvenile fibroadenomas of breast. Eur J Surg 2000; 166: 828- 30.

5. Greydanus DE, Parks DS, Farrel EG. Breast disorders in children and adolescents. Pediatr Clin North Am 1989; 36: 601 -39.

6. Davis C, Patel V. Surgical problems in the management of giant fibroadenoma of the breast. Am J Obstet Gynecol 1985: 152: 1010-5.

7. Raganoonan C, Fairbain JK, Williams S, Hughes LE. Giant breast tumours of adolescence. Aust NZ J Surg . 1987;57:243-7.
8. Greydanus DE, Matytsina L., Gains M., Breast disorder in children and adolescent. Prim care. $2006 ; 33(2): 455-502$.

9. Amiel C, Tramier D, Marck MF, et al. Le fibroadenome mamaire geant. J Gynaecol Obstet Biol Reprod 1993;22:764-5.

10. Kier LC, Hickey RC, Keetal WC, et al. Endocrine relationships in benign lesions of the breast. Ann Surg 1952;135:782-7.

11. Umekita Y, Yoshida $H$, lmmunohistochemical study of hormone receptor and hormone regulated protein expression in phylloides tumour: comparison with fibroadenoma. Virchows Arch 1998; 433: 3 1 1-4.

12. Katariya RN, Forrest APM, Gravelle I H. Breast volume in cancer of the breast. Brit J Cancer. $1974: 29(3) ; 270-273$.

13. Raganoonan C, Fairbain JK, Williams S, Hughes LE. Giant breast tumours of adolescence. Aust NZ J Surg 1987;57:243-7.

14. Carl D, Patel V. Surgical problems in the management of the breast tumour. Am J Obstet Gynecol 1985;152:1010-5.

15. Hart J, Layfield LJ, Trembull WE, et al. Practical aspects in the diagnosis and management of cystosarcoma phylloides. Arch Surg 1988;123:1079-83.

16. .McDonald JR, Harrington SW. Giant fibroadenoma of the breast (cystosarcoma phylloides). Ann Surg 1950;131-234.

17. Mies C, Rosen PP. Juvenile fibroadenoma with atypical epithelial hyperplasia. Am J Surg Pathol 1987; $11:$ 184-90. 